\title{
Investigating Needs to Develop Training in Precision Medicine for Frontline Healthcare Professionals: A Focus Group Study
}

\section{Sharon Mitchell ( $\square$ sharon.mitchell@iml.unibe.ch )}

Institute for Medical Education (IML), University of Bern, 3012 Bern, $\mathrm{CH}$

\section{Evrim Jaccard}

University Hospital CHUV

\section{Felix Michael Schmitz}

Institute for Medical Education (IML), University of Bern, 3012 Bern, CH

\section{Elianne Von Kanel}

Institute of Psychology, University of Bern, Fabrikstrasse 8, 3012 Bern, CH

\section{Prune Collombet}

Division and department of primary care medicine, Geneva University Hospital (HUG) Faculty of medicine, 1205 Geneva, $\mathrm{CH}$

\section{Jacques Cornuz}

Unisanté, Faculty of biology and medicine, University of Lausanne, 1011 Lausanne, CH

\section{Gérard Waeber}

Department of medicine, University Hospital CHUV, 1011 Lausanne, $\mathrm{CH}$,

Idris Guessous

Division and department of primary care medicine, Geneva University Hospital (HUG) Faculty of medicine, 1205 Geneva, $\mathrm{CH}$

\section{Sissel Guttormsen}

Department of medicine, University Hospital CHUV, 1011 Lausanne, $\mathrm{CH}$,

\section{Research Article}

Keywords: needs assessment, precision medicine, continuing professional development, conceptual frameworks, blended training

Posted Date: October 25th, 2021

DOI: https://doi.org/10.21203/rs.3.rs-995326/v1

License: (c) (i) This work is licensed under a Creative Commons Attribution 4.0 International License. Read Full License 


\section{Abstract}

Background: Precision Medicine offers tailored prevention, diagnosis, treatment and management to patients that considers genomic, lifestyle and environmental factors. If implementation of PM is to advance, effective, focused upskilling of frontline healthcare workers through quality continuing professional development (CPD) is needed. This study reports on an evidence-based approach to needs assessment to investigate the acceptability of pharmacists, advanced practice nurses and general practitioners towards a national blended training programme in PM. Needs assessment avoids a topdown approach and supports a design that is fit for purpose, acceptable to the target professions and fills a perceived gap in current practice.

Methods: This study reports on 2 focus groups $(n=12)$ delivered in French and German with equal professional participation of the targeted professions. The focus groups were audio recorded, transcribed by intelligent verbatim and translated to English. NVivo was used for data analysis and interpretation following a hybrid approach using the Framework Method and thematic analysis.

Results: Precision Medicine as a new topic is largely unfamiliar to frontline healthcare professionals. Insight was gathered on acceptable learning objectives and results will be validated with a follow up survey to a wider audience. All participants shared their concerns on their readiness to implement a precision approach within their professions. Additional raised points include insufficient system infrastructure and supporting network of experts, a lack of time to attend training, and a lack of clarity for use in practice.

Conclusions: Our results conclude that an adaptable and flexible training programme in PM is timely, contextually relevant and conducive to the needs of targeted health professions for successful implementation. A training programme in PM will require support across sectors and stakeholders, supporting insurance models, educated patients and integrated care supported by innovative technology. Precision Medicine is on our horizon and it is not a question of if but when and to what extent Precision Medicine will become a new normal for frontline healthcare professionals.

\section{Background}

New strains on healthcare systems including access to trained healthcare workers have prompted discourse on how healthcare delivery must change to meet demands of more complex diseases, new knowledge and skills and evolving technology [1]. Delivery of quality, easy to access learning opportunities are essential if healthcare systems are to effectively meet these demands. Delivering the right approach, for the right patient at the right time, could lead to more effective, efficient health systems with better patient outcomes [2], an approach known as Precision Medicine (PM). PM considers individual needs, variability in genomes, the environment and lifestyle [3] for more precise diagnostics, treatment and management plans. The global health stage is calling for impending change to current practice-care delivery (Bernaert, 2021). The promise of PM offers more targeted care pathways for 
patients, built on foundations of inter-professional collaboration [4]. Yet promise of this approach is dampened by critics questioning whether expectations of PM is outpacing clinical reality [5]. Healthcare professionals are not yet ready to implement a more genome-driven approach to patient care [6].

Effective training may provide one of the keys to unlocking the challenges of implementation. The design of a training programme requires an approach to continuing professional development (CPD) that is acceptable and appropriate to frontline healthcare professionals including general practitioners, advanced practice nurses (APN), and pharmacists. CPD training programmes are tainted by design that is ad hoc, and top-down [7], with little follow-up or known impact in clinical practice [8]. Carefully planned needs assessment as a first step offers a systematic path to assess the perceived gap between existing competencies and those required for clinical daily practice [9].

The use of conceptual frameworks in learning development 'illuminate and magnify' research objectives that guides development of training programme design [10]. The atypical approach to adopt Kirkpatrick's evaluation model [11] as a basis to launch our research is a noted salute to the well-known phrase 'begin with the end in mind' [12]. The Kirkpatrick evaluation model has been modified to investigate needs with 4 questions mapped from Kirkpatrick's levels of evaluation (figure 1). Reaction to KNOWLEDGE GAP investigates reactions to a topic area and determines pre-existing knowledge, learning as LEARNING investigates perceived acceptance of proposed learning objectives and teaching methods, behaviourto POTENTIAL considers the perceived need of training in clinical practice and impact to MOTIVATION investigates sustainability and factors that support or hamper impact.

This project aims to support growing evidence and best practice in the design of training for CPD. Guided by conceptual frameworks, this needs assessment investigates the perceived needs of target professionals towards PM to inform evidence based education design, with the intention of implementation of a blended training programme.

\section{Methods}

Ethical approval was granted by the Swiss Cantonal Ethics Board in April 2020. Using FG for needs assessment is well established [13]. The preparation of the FGs followed a design structure purported by Nagel and Williams 2013 [14].

\section{Preparation of the FG}

Preparation included a workshop with 5 inter-professional members of the project team. Results of the workshop led to RQ1, RQ2, RQ3 and RQ4 (figure 1). RQ1 \& RQ2 required a literature review [15] to propose content specific information about PM with two objectives. First, to derive a definition of PM, a member of the research team searched through databases including PubMed, Medline, Google (also -Scholar and books) with the following key terms: PM in Primary Care/ Personalised Medicine in Primary Care/ Genomics in Primary Care/ Pharmacogenomics. The researcher logged publications based on opinion of 
relevance, formal and informal qualitative and quantitative studies, literature reviews and year of publication (2014 to 2020) [16]. From 21 selected publications, 6 publications were used to describe PM $[3,6,17-20]$ as a process that takes into account individual preferences, variability in the genome, environment and lifestyle in order to tailor prevention interventions, diagnosis techniques and treatment strategies to improve health outcomes. Second, to prepare a list of learning outcomes for a training programme in $\mathrm{PM}$, a literature review guided content development (Appendix 1). The process was led by a physician with advanced knowledge in PM and included consultation within the project team. A rating scale was designed to allow participants to rate each learning outcome from 1 (not at all important to my profession) to 10 (extremely important to my profession).

To investigate RQ3, the research team prepared 3 patient cases integrating a precision approach to care specific to general practitioners, APNs and pharmacists. These cases were refined after feedback from the research team. No preparatory steps were required for RQ4. Questions linked to motivation were explored onsite.

The question route was piloted with two family doctors and a pharmacist in Switzerland, and an applied practice nurse in Ireland. These participants were not included in the FGs. This process tested how questions were understood, an approximate time and overall impressions. The question route was refined based on feedback (Appendix 2). Practice rehearsals were held in German and French with materials and props, following reported best practice [21].

\section{Participants and researchers}

Participants included 4 general practitioners, 4 APNs, and 4 pharmacists $(n=12)$ equally distributed across both FGs. By design, it was decided not to include an additional 3 participants to each FG to ensure a flow of conversation and follow best practice in FG size [22]. The participants were recruited by project leaders (Professors of internal medicine, family medicine and medical education). Purposeful sampling was applied [23], considering years' experience (one participant per profession relatively early career, and one later in their career), gender (balanced in each group), as well as clinical experience and regular patient contact.

Researchers included 4 physicians with a special interest in PM (JC, IG, GW, EJ), 3 medical educationalists (SG, FS, SM), and 1 psychology research student and registered nurse (EV), and a project coordinator (PC). Members of the research team were assigned roles; a moderator (FS, EJ), a comoderator (EJ, SM), a note-taker (EV) and a content expert (EJ), following a best practice approach [24]. Practice sessions ensured all research team members became familiar with their roles, the content and techniques to encourage participants to share their views in a comfortable environment [25] and for consistency in data collection [26].

\section{Design}


Two inter-professional FGs were delivered in Bern (in German) and in Lausanne (in French), following the same design. The question route was guided by pre-prepared activities facilitated by a moderator (Appendix 2). Consistency across both FGs was maintained by ensuring that all supporting materials, charts, question route and group activities were prepared in English and translated in German and French by the same (bilingual) researcher. Participants received no content information about the research project before their participation.

\section{Data collection}

The two FGs were delivered face-to-face following pandemic safety guidelines in August and September 2020. Both FGs were planned for 3 hours and ran over time but not beyond 15 additional minutes. The FG activities and discussions were audio recorded. Visual analogues, write on post-its, and survey were used. All visual results were photographed or collected onsite.

\section{Data analysis}

Recordings of the FGs were transcribed in German and French, translated into English and passages of the text back-translated [27]. SM and PC discussed key concepts of specific passages, aligning final agreement on more ambiguous passages [28]. The data from both FGs were analysed using the Framework method of analysis [29] and thematic analysis [30].

The Framework method of analysis guides data collection identifying a priori themes in a deductive top down approach. This method also recognises new data from guided discussion [29]. Using thematic analysis to identify inductive themes brings these approaches together in a practical marriage of two analytical frameworks. This exploratory research design applies conceptual frameworks as a tool to bring structure and coherence [31]. The rationale for this hybrid approach (figure 3) is grounded within the overarching research objectives, to apply an analytical framework to converge investigative themes with key questions for needs-assessment andto better understand perceptions towards PM.

NVIVO was used for data analysis [32]. After familiarizing with the transcripts, SM identified and organised codes and patterns within predetermined themes presented by Kirkpatrick's model characteristic of the Framework method [29]. New inductive codes were generated by NVIVO. The codes were sorted by SM and potential sister themes to the original question route or sub-themes to new or existing topic areas were presented (figure 3). Conducive with the Framework Method to compare groups using matrices, SM investigated differences across professional groups and FG settings. The codes were discussed in weekly meetings between January 2021 and March 2021, in which SM, EJ, FS, and SG refined codes. EJ blindly rated one full FG for interrater reliability by investigator triangulation [33]. SM kept a visual coding logbook throughout the process, noting the decision trail to themes and an organising structure outlining rationale for decisions [34]. This resulted in a visual progression of results, with evolving themes and sub-themes that could be tracked and shared across the research team. 


\section{Results}

Built on the principles from Figure 3, results are presented in two sections (figure 3). Themes that inform training programme design present findings from 4 a priory themes (figure 3 ) aligned to the Framework Method with inductive sub-themes [29]. The right section presents an additional 3 themes that inform implementation identified through inductive thematic analysis. Results of visual analogues are presented using ranked levels of interest from 1 not at all interested to 10 very interested.

\section{Themes that inform training programme design}

Using NVIVO, the research team investigated differences across professions and settings. No differences were found. Four of the themes correspond to the research questions (Fig 1. and Fig. 4). The iterative process of verifying themes strengthens credibility, whereby themes determined by researchers appropriately fit FG discussions [35].

Knowledge gap

One objective was to explore the assumption that frontline health care workers are not well informed about PM. This assumption was confirmed whereby participants $(n=6)$ self-reported that they had not previously heard of PM, none had seen patients asking for genomic sequencing and none had seen patients that presented with a genetic data.

There's a huge gap, I'm starting from nothing

All participants agreed and accepted the presented description and definition of PM (see section 2.1) with the proposed change of replacing 'process' with 'approach'.

The practical application of genomic testing was discussed, e.g. when it was appropriate to do a genome sequence, how that information should be managed and shared with patients, raising questions on how best to translate genomic data to better patient outcomes. Results confirm our knowledge gap assumptions.

Learning

A comparison between the professions showed that there was high agreement on relevance of the presented learning objectives (Table 1: mean agreements between 9.75 and 6.25 of Scale $1-10$ where $10=$ extremely important to my profession). Further data was collected regarding the specific learning objectives within each of the presented topic areas (ref. supplementary materials). For the purpose of limitations of the study we have An additional subtheme on the type and form of training emerged reflecting expectations in practice. Doubt arose concerning the implications of bringing this topic into practice and the need to train in a topic that is not well defined. Given the nature of PM as an integrated approach to care, participants supported inter-professional training; 
It would be an advantage to have a common training ... as participants have to work together, so why not learn together... ....There might be a common foundation... ....and we can address specific roles [general practitioners, pharmacist, applied practice nurse].

Flexible learning adaptable to different professions with different needs was found as a challenge. Our findings highlighted that every participant had different expectations and preferences, underlying the importance of a design that is adaptable to every learner.

\section{Table 1. Perceived level of importance of PM learning objectives by professional role}

Rating scale 1 (not at all important to my profession) to 10 (extremely important to my profession)

1] Use basic genetics knowledge and family history to integrate genomic risk into the health care plan $\$$

2] Communicate and act on the possibilities, limitations and challenges of PM when integrated in the health care plan\$

3] Understand genomic sequencing information and consider/highlight its potential impact on health when counselling patients\$

4] Understand the relative contribution of behavioural, social, and environmental factors in health and disease and act on them to improve the health status of your patient ${ }^{\$}$

5] Understand and apply societal and legal implications of $\mathrm{PM}^{\$}$

6] Understand the clinical features and the therapeutic options associated with the most frequently encountered diseases of your specialty that are caused by genomic variants\$

7] Manage/coordinate care with PM services\$

$9.00 \pm$

0.50

9.75
0.25
$9.75 \pm$

0.25

$9.75 \pm$

0.25

$8.00 \pm 1.50$

$6.75 \pm 1.00$

$9.25 \pm$

0.50

$8.25 \pm 0.75$

$8.00 \pm$

1.25

$8.00 \pm$

1.50

$8.50 \pm$ 1.25

Physicians

$\begin{array}{lll}9.75 \pm & 7.75 \pm 1.50 & 8.25 \pm \\ 0.25 & & 1.25\end{array}$

1.25
$9.75 \pm$
0.25
$8.00 \pm 1.25$
$8.00 \pm$
1.25

$\$$ Results are mean \pm Standard error of the mean $(\mathrm{SEM}) . \mathrm{N}=12$

Potential

The patient scenarios triggered discussions on the practicalities of professional roles. Participants rated these scenarios resulting in high agreement of relevance within each profession ( $\max 9.5, \min 8.0$ ). Limitations included a lack of vision on how to implement PM, lack of clarity on clinical outcomes for patients, and access to patient records.

'So for the pharmacist scenario...... we don't have access to patients' medical records and we are fighting for that, because that would increase the safety with which we dispense medication'. 
Risks of implementing a PM approach that could potentially have a negative impact included big data, safe collection and storage of data, and the risk to patients.

At the level of accessibility of data .... We may end up with a massive amount of information and then we need to know how to interpret it.... and make the right decisions.

Challenges were identified as a lack of time, lack of resources, how to share information, absence of a clear definition. Many of these challenges were repeatedly expressed throughout discussions.

We are actually overwhelmed with all the things we should do in this short consultation. 30 minutes is too short, it takes a whole hour for this kind of patient.

Strengths With a focus on improving practice performance and patient outcomes, participants discussed the potential of PM in patient care regarding new requests from patients and hospitals, promotion of better integration and inter-professionalism, early intervention and better patient management.

The professional organisation in which I am involved is generally favourable to progression towards PM and to the inclusion of PM in our logic. This organisational system would promote opening towards innovation in patient management.

\section{Motivation}

Although the current perceived importance of PM were ranked as low (indicated in average as 1), all professional groups indicated an increased importance of PM as well as increased level of interest in the future (between 4.5 and 8.2). A lack of readiness from insurance, patients and health systems were all identified as possible roadblocks to successful implementation.

Investigating the motivation in PM brings us to the centre of determining acceptance and appropriateness to a move towards a genome driven approach to patient care.

I would say ..., that my degree of interest (for PM training) would depend ultimately to what extent PM enters into [clinical] guidelines.

\section{Themes that inform implementation}

The below themes are presented from the results of the thematic analysis (figure 4). These themes are organised within this section to support interventions to facilitate implementation.

\section{Patients}

The implementation of a more precision approach to patient care could not be successful without interest from patients. 
If I didn't have interest from patients..., I wouldn't be interested.

Education in PM can equip patients to make life choices that may reduce risk of disease presentation.

It is not enough to have the right tool which gives the right intention, you have to help the person go in the right direction

An educated patient who is willing to have their genome sequenced and is open to discuss how to reduce and identify risks through lifestyle choices and preventive medication may benefit from an extended and healthy life. These discussions ventured towards the risks of a more precision approach to quality of life for patients.

We are battling against disease characteristics within the patient that will remain throughout their life and that we cannot eliminate.... We can only act against, act with or adopt behaviour that is more favourable, but we cannot eliminate the problem.

All participants agreed that this was a delicate balance that still left unanswered concerns.

Health Systems

The participants understand PM as a care approach that is integrated through professional networks that facilitate a patient's care transition across healthcare settings.

The more inter-professional interaction there is, the better the integration....by managing as a network we integrate more.

Integrated care is dependent on inter-professional practice, availability of patient data across settings, and communication channels.

Around costs, two diverging perspectives emerged; the additional costs of genetic testing and support treatments and the delivery of more efficient medicine that may yield better patient outcomes. The potential of implementing an individualised approach will be restricted by current infrastructure, particularly with patient health insurance. In a number of scenarios PM requires support of many healthcare professionals.

If it leads to the consultation of a dietician [for example] if I look at today's reality, the patient costs will not be covered.

\section{Professionalism}

The risks of implementing a more genome centred approach surfaced discussions on the need for clear guidance to safeguard patients. In this instance, the collection, storing and disseminating patient data, risk of quality of life to patients and safe decision making. 
In the end is there not a risk of selecting individuals who deserve to be treated based on their genome? ... [Precision Medicine]... should be implemented ethically and to the highest standards.

The movement of professional boundaries is evolving in current delivery of care to patients. Professional roles are not always clearly defined and sometimes dictated by legal restrictions rather than capabilities of professionals or what makes sense in practice.

The pharmacists are currently redefining their profession and the neighbourhood pharmacist is a gateway to the healthcare system.

Participants demonstrated a commitment to delivering the best care to patients through professional identity and ownership of tasks.

In inter-professional work there are two dimensions which are important. One is to work with the other person... the other is to fully understand one's own identity and be able to communicate it to others.

\section{Discussion}

Perhaps our greatest finding is that introducing a new approach to care, beyond an update of knowledge or skills, requires consideration of interventions that will scaffold education to facilitate effective integration of PM into clinical practice.

\section{Themes that support training programme design}

The choice of Kirkpatrick's evaluation framework as a guide to investigate four main questions (figure 1) proved to be an insightful approach to gather input on acceptability and appropriateness of proposed training.

\section{Knowledge gap}

Participants were unfamiliar with the application of PM in practice. The PM knowledge gap among healthcare professionals has been explored as a potential barrier to implementation [36]. Our findings reported perceived limited evidence of clinical usefulness and limited understanding, a finding also found specifically within Primary Care. Yet the integration of PM in practice is not so much a question of if, rather of when, and to what degree to apply a PM approach to patients [37]. Our findings support the need to design a training that increases knowledge of PM with practical examples of use to targeted professional roles. A noted reflection on participants self-reported knowledge gap is that many of the topics raised perfectly reflect reported challenges of PM. It draws on an inconsistency between the reported gap in knowledge from our participants and the accuracy of discussion areas, and supporting interventions. The researchers deduce that the reported gap in knowledge specifically relates to more practical application of PM in clinical practice. More targeted research is needed.

\section{Learning}


We found an acceptance of proposed learning objectives across professions. Inter-professional learning was discussed as the preferred approach, with implications for content; 'as participants have to work together, so why not learn together'. Congruent with findings in the literature, practical implementation relies on inter-professional education that will support communication across settings in a robust integrated care delivery [38]. A potential critique of our findings indicates that a favour towards interprofessional learning is an effect of the inter-professional mix of the groups, rather than a real need. As the literature supports an inter-professional approach to deliver PM, this potential bias has little substance.

Online and blended learning approaches are deemed most favourable to meet the demands of busy healthcare professionals [39]. Yet there is notable absence of evidence on what constitutes effective learning for this targeted group [40]. Further evidence is needed to determine what teaching methods are effective to bring measurable impact and improved care to patients in clinical practice [41]. Our findings add to a call for more flexible, adaptable and a blended approach to learning in CPD [42]. This needs assessment has enabled designers to test the waters with a structure and content for training in a topic largely unknown in frontline healthcare. The intended next steps will be to present a more refined training programme to wider targeted professions for validation.

\section{Potential}

Participants largely viewed PM as an innovative approach to care, which also aligns to previously published articles on healthcare innovation through PM [43]. In this way PM does not seek to address one specific healthcare gap in practice, rather to promote and implement innovation in patient care. Obstacles to introducing approaches in medicine are not new, and therefore should also be considered within the context of this project. Health systems are struggling to keep pace with innovation and innovation disrupts delivery of care in already overstretched healthcare systems [44]. Building on previously published literature, our findings support that within new or innovative approaches to care, additional caution is required to overcome inherent challenges in design and implementation [45]. Results add to the validity of results including unprecedented data volumes, interpreting data at the level of the individual and integration into the clinic [37]. Covering these topics within a targeted training programme will equip frontline healthcare workers with the know-how and skills to overcome barriers and maximise the potential of PM until this approach evolves past infancy and healthcare systems can fully support implementation.

\section{Motivation}

The willingness of participants to engage in training on PM will depend on the extent to which PM enters into clinical guidelines, indicative of previously published case-studies whereby evidence based medicine drives innovation in healthcare $[46,47]$. While the quality of a training programme in PM might merit interest, long-standing success must take into account that science can drive policy change and motivation. Yet original research is glaringly absent in the field [48]. Targeted clinical guidelines based on efficacy and effectiveness of PM in practice can provide one of the keys to unlocking successful 
implementation of a precision approach to patient care [38]. The driver behind this dissemination will be the efforts of healthcare professionals to ensure that clinical practice reflects the best current evidence through continuing education.

\section{Themes that support implementation}

The organisation of themes followed a natural transition and distinction between what is needed to deliver a high-quality training, and what is needed to deliver a sustainable programme in PM. This section addresses the latter and reflects discussions during the FG.

\section{Patients}

Our findings open the door to essential considerations to educate patients and build awareness in PM. 'It's not enough to have the right tool for the right intention, you have to support that person to go in the right direction'. A reported lack of understanding and awareness of PM among patients and public continues to be reported [49]. New studies are presenting refreshing insights that most patients are willing to share their data and biospecimens for research [50], and so accepting PM as an approach in practice. These findings echo the growing role of patient involvement as a catalyst for change [51]. For PM to fit to clinical practice, awareness and education are essential to train patients to absorb complex information about their health to enable them to make informed choices [52]. Additional interventions to increase knowledge about PM among patients will support the overall impact of this training.

\section{Health systems}

Participants identified the role of inter-professional practice as a prerequisite to precision patient care, describing examples of a PM friendly care system that strengthens communication, shares patient data safely across settings, and facilitates a network of experts. Participants agreed that building a network of professionals can mobilize multi-professional teams to foster integration across healthcare settings. These findings are consistent with effective patient interventions that rely on integrated care across clinical settings [53]. PM cannot expect to be integrated into insurance models without proof of costefficiency. These issues support a recently published report questioning whether PM facilitates better healthcare [54]. This report is contextually relevant for the Swiss system and calls for the need to reform insurance payment systems, making patients responsible and PM affordable. It offers potential solutions to an economic infrastructure already being considered by insurance, pharmaceutical, academic research, regulators and patients. Precision Medicine: A Global Action Plan for Impact, reports on national strategic implementation plans across 17 countries, including considerations for economic impact analysis [55]. Relevance of findings are not only limited to Switzerland. Similar investigative efforts on readiness, economic evaluations and partnerships to drive support technology from multiple stakeholder perspectives, are being reported world over $[19,56]$.

\section{Professionalism}


PM requires the highest quality professionalism in a coordinated effort across professions. According to participants, the future of PM could fly or fail based on the desire of professionals to move beyond current practice, take ownership for tasks (that should be revisited within professional roles) with a strong professional identity that supports practice precision for patients. The role of professionalism will require facilitation and empowerment of professions based on capability rather than restrictions imposed for legal or financial implications. Further research may shed light on the importance of professional identity as a success factor to implementation. Ineffectiveness in delivery brings risks to patients as well as ethical implications [57]. We have documented challenges resonating with participant's reports on the need to safely store and disseminate patient data, facilitate safe decision making and offer accessibility to all patients without barriers. Safeguarding patients from the risks of privacy and discrimination [58], empowerment to make decisions [59] and access [60] requires thoughtful consideration of a new approach to care that is patient centred.

\section{A role for implementation science in education design}

For education to be effective, it must be implemented well. It therefore makes sense that a methodological process for implementation actively supports training programme delivery. Through a new lens of the resultant themes and a revisited review of the literature, our findings show that all themes fit to implementation outcomes, within the discipline of implementation science. This approach highlights that a quality innovation does not guarantee uptake, and a facilitation of the transition from research to practice is essential [61].

Relevant to our research are the constructs of acceptability, appropriateness and feasibility (Figure 4). Implementation outcomes serve as indicators for success and in the design phase offers preconditions for attaining desired change [64]. To determine whether a training programme is successful, there is a need to evaluate the training programme as well as implementation in practice; the outcomes and impact [65]. Further research should evaluate the relevance of implementation science as a conceptual framework for design of education interventions.

\section{Practical considerations}

Qualitative research has limitations of objectivising facts and more FGs could have been run to substantiate themes. Our objective was to provide insights on reactions and potential for PM, proposed content and structure for CPD and motivation to adopt a PM approach. Despite the sample size of 2 FGs, insights illustrated synergetic results and met the research objective with the intention to deliver a follow up survey addressing a larger population to substantiate results. Needs assessment must be practical. The research team continued development of a training programme during the results analysis where needs assessment continually informs content development.

Use of conceptual frameworks have been the underlining thread guiding the project team positioning final results within the context of broader literature, adding meaning and reflection to findings [10]. The research scope has limited investigations to targeted professions. Further stakeholders including patients, policy makers, educators, and health economic experts will need to be involved for Precision 
Medicine to reach its potential as an accepted approach to patient care. Reflections on results add to convincing arguments for the practical application of implementation science outcomes in education design [66].

\section{Conclusion}

This project set out to design an effective training programme in PM. A structured approach to needs assessment using conceptual frameworks for design has proven effective to these project expectations: to find an acceptable, appropriate and feasible solution for design and implementation. Investigating the knowledge gap in PM supports initial assumptions that the topic is not well understood. An adaptable training programme that is flexible to individual needs is favoured to drive learning. The potential of the programme should be driven by the perceived fit and relevance to practice. Engagement is determined by specific motivating factors that can support implementation including strengthening inter-professional learning, integrated care across settings, safeguarding patients and patient data, improving awareness and education in the topic, continuing evidence based research and revising economic barriers and insurance models. A design of a practical training underlining the foundations of PM and case examples of how this approach translates to clinical practice was deemed most useful and favourable. These findings deliver insights for how to deliver an effective education programme in PM. Although this study took place in Switzerland, outcomes appear relevant beyond the national borders. An essential facet being the selection and implementation of a meaningful conceptual framework for needs assessment for innovative educational interventions. The promise of precision frontline healthcare will rest on a number of crucial factors, of which targeted education remains essential.

\section{List Of Abrievations}

APN - advanced practice nurse

CPD - continuing professional development

PM - Precision Medicine

SEM - Standard Error of the Mean

F/G - French/German

\section{Declarations}

- Ethics approval and consent to participate

Ethical approval was granted by the Swiss Cantonal Ethics Board in April 2020 approved reference Req2020-00166. All methods were performed in accordance with the Swiss ethical guidelines and regulations swissethics.ch and in line with the Declaration of Helsinki. 
- Consent for publication

All participants signed a declaration for consent before any data was collected.

- Availability of data and materials

The dataset(s) supporting the conclusions of this article is available from the author on request by emailing the corresponding author.

- Competing interests

There are no competing interests to be declared

- Authors' contributions

All researchers played a role in the design, delivery and subsequent analysis of the data. More specifically, the project team include 4 physicians with special interest in Precision Medicine (JC, IG, GW, EJ), 3 medical educationalists (SG, FS, SM), and 1 psychology research student and trained applied practice nurse (EVK), as well as a project coordinator (PC). The team met in regular project meetings to discuss the content and planning, research design, data analysis, and results (SG, SM, EJ, EVK, FS). The development of a definition of PM was presented based on the literature and discussed and refined (IG, JC, GW, EJ, SM, PC). Members of the research team were assigned specific roles during the focus groups: a moderator (FS, EJ), a co-moderator (EJ, SM), a note-taker (EVK) and a content expert (EJ). A scientist familiar with the project was there to observe and note overall observations and step into a role if needed (DS, SM). In order to ensure consistency across the two focus groups, we were able to organise multilingual $(F / G)$ members of the team (EVK, EJ). They could actively take part in discussions across both focus groups and across different allocated roles. The team members, as authors of this article, reviewed several versions of the article (SG, FS, EJ, SM, IG) and approved it for submission (all).

- Funding

This research has been financially supported by Health2030, a consortium of University Hospitals and Universities based in Switzerland. This research is conducted independent of any influencing factors of Health2030.

- Acknowledgements

The authors would like to thank Health2030, the participants of the study and all those who support the preparation for this research.

\section{References}

1. Kringos DS, Boerma WG, Hutchinson A, Saltman RB: Building primary care in a changing Europe: WHO Regional Office for Europe; 2015. 
2. Tsimberidou AM, Hong DS, Wheler JJ, Falchook GS, Naing A, Fu S, Piha-Paul SA, Janku F, Cartwright C, Broaddus R: Precision medicine: Clinical outcomes including long-term survival according to the pathway targeted and treatment period-The IMPACT study. In.: American Society of Clinical Oncology; 2018.

3. Collins FS, Varmus H: A new initiative on precision medicine. N Engl J Med 2015, 372(9):793-795.

4. Reeves S, Pelone F, Harrison R, Goldman J, Zwarenstein M: Interprofessional collaboration to improve professional practice and healthcare outcomes. Cochrane Database of Systematic Reviews 2017(6).

5. Rubin R: Precision medicine: the future or simply politics? Jama 2015, 313(11):1089-1091.

6. Feero WG: Is "Precision Medicine" Ready to Use in Primary Care Practice? Yes: It Offers Patients More Individualized Ways of Managing Their Health. Am Fam Physician 2017, 96(12):767-768.

7. Chorley A, Azzam K, Chan TM: Redesigning continuing professional development: Harnessing design thinking to go from needs assessment to mandate. Perspectives on Medical Education 2020:1-6.

8. Asch DA, Weinstein DF: Innovation in medical education. N Engl J Med 2014, 371(9):794-795.

9. Prideaux D: Curriculum design. Bmj 2003, 326(7383):268-270.

10. Bordage G: Conceptual frameworks to illuminate and magnify. Med Educ 2009, 43(4):312-319.

11. Barr H, Freeth D, Hammick M, Koppel I, Reeves S: The evidence base and recommendations for interprofessional education in health and social care. J Interprof Care 2006, 20(1):75-78.

12. Covey SR: The 7 habits of highly effective people, vol. 1: Simon \& Schuster New York; 1989.

13. Tipping J: Focus groups: a method of needs assessment. Journal of Continuing Education in the Health Professions 1998, 18(3):150-154.

14. Williams N, Nagle B: Methodology Brief Introduction To Focus Groups. Center for Assessment, Planning \& Accountability Retrieved August 2013, 8.

15. Grant MJ, Booth A: A typology of reviews: an analysis of 14 review types and associated methodologies. Health Info Libr J 2009, 26(2):91-108.

16. Druery J, McCormack N, Murphy S: Are Best Practices Really Best? A Review of the Best Practices Literature in Library and Information Studies. Evidence Based Library and Information Practice 2013, 8:110-128.

17. Collins H, Calvo S, Greenberg K, Forman Neall L, Morrison S: Information Needs in the Precision Medicine Era: How Genetics Home Reference Can Help. Interact J Med Res 2016, 5(2):e13.

18. Ramaswami R, Bayer R, Galea S: Precision Medicine from a Public Health Perspective. Annu Rev Public Health 2018, 39:153-168.

19. Ginsburg GS, Phillips KA: Precision medicine: from science to value. Health Affairs 2018, 37(5):694701.

20. Carroll JC, Makuwaza T, Manca DP, Sopcak N, Permaul JA, O'Brien MA, Heisey R, Eisenhauer EA, Easley J, Krzyzanowska MK et al: Primary care providers' experiences with and perceptions of personalized genomic medicine. Can Fam Physician 2016, 62(10):e626-e635. 
21. Adams A, Cox A: Questionnaires, in-depth interviews and focus groups. Research Methods for Human-Computer Interaction 2008:17-34.

22. Barbour R: Doing focus groups. London: Sage; 2008.

23. Benoot $C$, Hannes $K$, Bilsen $J$ : The use of purposeful sampling in a qualitative evidence synthesis: $A$ worked example on sexual adjustment to a cancer trajectory. BMC medical research methodology 2016, 16(1):1-12.

24. Stalmeijer RE, McNaughton N, Van Mook WN: Using focus groups in medical education research: AMEE Guide No. 91. Medical teacher 2014, 36(11):923-939.

25. O. Nyumba T, Wilson K, Derrick CJ, Mukherjee N: The use of focus group discussion methodology: Insights from two decades of application in conservation. Methods in Ecology and evolution 2018, 9(1):20-32.

26. Krueger RA: Focus groups: A practical guide for applied research: Sage publications; 2014.

27. Esposito N: From meaning to meaning: The influence of translation techniques on non-English focus group research. Qualitative health research 2001, 11(4):568-579.

28. Chen HY, Boore JR: Translation and back-translation in qualitative nursing research: methodological review. Journal of clinical nursing 2010, 19(1-2):234-239.

29. Gale NK, Heath G, Cameron E, Rashid S, Redwood S: Using the framework method for the analysis of qualitative data in multi-disciplinary health research. BMC Medical Research Methodology 2013, 13(1):117.

30. Braun V, Clarke V: Using thematic analysis in psychology. Qualitative research in psychology 2006, 3(2):77-101.

31. Casula M, Rangarajan N, Shields P: The potential of working hypotheses for deductive exploratory research. Quality \& Quantity 2020:1-23.

32. Hilal AH, Alabri SS: Using NVivo for data analysis in qualitative research. International interdisciplinary journal of education 2013, 2(2):181-186.

33. Archibald MM: Investigator triangulation: A collaborative strategy with potential for mixed methods research. Journal of mixed methods research 2016, 10(3):228-250.

34. Koch $\mathrm{T}$ : Establishing rigour in qualitative research: the decision trail. Journal of advanced nursing 1994, 19(5):976-986.

35. Tobin GA, Begley CM: Methodological rigour within a qualitative framework. Journal of advanced nursing 2004, 48(4):388-396.

36. Haga SB, Kim E, Myers RA, Ginsburg GS: Primary care physicians' knowledge, attitudes, and experience with personal genetic testing. Journal of personalized medicine 2019, 9(2):29.

37. Duffy DJ: Problems, challenges and promises: perspectives on precision medicine. Briefings in bioinformatics 2016, 17(3):494-504.

38. Haga SB, Mills R, Aucoin J, Taekman J: Interprofessional education for personalized medicine through technology-based learning. Personalized medicine 2015, 12(3):237-243. 
39. Holloway K, Arcus K, Orsborn G: Training needs analysis-The essential first step for continuing professional development design. Nurse education in practice 2018, 28:7-12.

40. Mealey E: Developing an online continuing professional development course for busy healthcare professionals: 12 tips for course developers. MedEdPublish 2019, 8.

41. Huang $\mathrm{P}-\mathrm{H}$, Haywood M, O'Sullivan A, Shulruf B: A meta-analysis for comparing effective teaching in clinical education. Medical teacher 2019, 41(10):1129-1142.

42. Nancarrow SA: Six principles to enhance health workforce flexibility. Human resources for health 2015, 13(1):1-12.

43. Qoronfleh MW, Chouchane L, Mifsud B, Al Emadi M, Ismail S: THE FUTURE OF MEDICINE, healthcare innovation through precision medicine: policy case study of Qatar. Life Sciences, Society and Policy 2020, 16(1):1-20.

44. Dixon-Woods M, Amalberti R, Goodman S, Bergman B, Glasziou P: Problems and promises of innovation: why healthcare needs to rethink its love/hate relationship with the new. $B M J$ quality \& safety 2011, 20(Suppl 1):i47-i51.

45. Hudson JN, Farmer EA, Weston KM, Bushnell JA: Using a framework to implement large-scale innovation in medical education with the intent of achieving sustainability. BMC medical education 2015, 15(1):1-9.

46. Charlton V, Rid A: Innovation as a value in healthcare priority-setting: the UK experience. Social justice research 2019, 32(2):208-238.

47. Prasad V, Obley A: Is" Precision Medicine" Ready to Use in Primary Care Practice? No: It Is Barely Ready for Testing. American family physician 2017, 96(12):769-770.

48. Jaccard E, Cornuz J, Waeber G, Guessous I: Evidence-Based Precision Medicine is Needed to Move Toward General Internal Precision Medicine. Journal of general internal medicine 2018, 33(1):11-12.

49. Miller FA, Hayeems RZ, Bytautas JP, Bedard PL, Ernst S, Hirte H, Hotte S, Oza A, Razak A, Welch S: Testing personalized medicine: patient and physician expectations of next-generation genomic sequencing in late-stage cancer care. European Journal of Human Genetics 2014, 22(3):391-395.

50. Kim J, Kim H, Bell E, Bath T, Paul P, Pham A, Jiang X, Zheng K, Ohno-Machado L: Patient perspectives about decisions to share medical data and biospecimens for research. JAMA network open 2019, 2(8):e199550-e199550.

51. Olsen L, Aisner D, McGinnis JM: The learning healthcare system: workshop summary. 2007.

52. Hunter DJ: Uncertainty in the era of precision medicine. The New England journal of medicine 2016, 375(8):711-713.

53. Orlando LA, Henrich VC, Hauser ER, Wilson C, Ginsburg GS: The genomic medicine model: an integrated approach to implementation of family health history in primary care. Personalized medicine 2013, 10(3):295-306.

54. Nursimulu A, Florin M-V: Workshop Report: The Economics of Precision Medicine. In.: EPFL IRGC; 2018. 
55. Dzau V, Ginsburg GS, Finkelman E, Balatbat C, Flott K, Prestt J: Precision Medicine A Global Action Plan for Impact. WISH Forums Reports: World Innovation Summit for Health 2016.

56. Ong S, Ling J, Ballantyne A, Lysaght T, Xafis V: Perceptions of 'Precision'and 'Personalised'Medicine in Singapore and Associated Ethical Issues. Asian Bioethics Review 2021, 13(2):179-194.

57. Clayton EW: Ethical, legal, and social implications of genomic medicine. New England Journal of Medicine 2003, 349(6):562-569.

58. Stiles D, Appelbaum PS: Cases in precision medicine: concerns about privacy and discrimination after genomic sequencing. Annals of internal medicine 2019, 170(10):717-721.

59. Wynn RM, Adams KT, Kowalski RL, Shivega WG, Ratwani RM, Miller KE: The patient in precision medicine: a systematic review examining evaluations of patient-facing materials. Journal of healthcare engineering 2018, 2018.

60. Juengst ET, Settersten RA, Fishman JR, McGowan ML: After the revolution? Ethical and social challenges in 'personalized genomic medicine'. Personalized medicine 2012, 9(4):429-439.

61. Bauer MS, Kirchner J: Implementation science: what is it and why should I care? Psychiatry research 2020, 283:112-376.

62. Lewis CC, Weiner BJ, Stanick C, Fischer SM: Advancing implementation science through measure development and evaluation: a study protocol. Implementation Science 2015, 10(1):1-10.

63. Weiner BJ, Lewis CC, Stanick C, Powell BJ, Dorsey CN, Clary AS, Boynton MH, Halko H: Psychometric assessment of three newly developed implementation outcome measures. Implementation Science 2017, 12(1):1-12.

64. Proctor E, Silmere H, Raghavan R, Hovmand P, Aarons G, Bunger A, Griffey R, Hensley M: Outcomes for implementation research: conceptual distinctions, measurement challenges, and research agenda. Administration and Policy in Mental Health and Mental Health Services Research 2011, 38(2):65-76.

65. Kelly B, Perkins DF: Handbook of implementation science for psychology in education: Cambridge University Press; 2012.

66. Moir T: Why is implementation science important for intervention design and evaluation within educational settings? In: Frontiers in Education: 2018: Frontiers; 2018: 61.

\section{Figures}


RQ4: What is the level of interest and motivation towards Precision Medicine?

MOTIVATION

RQ3: What is the perceived potential of Precision Medicine among the target professions?

RQ2: What content and structure for Precision Medicine training is acceptable to target professions?

RQ1: What is the current knowledge gap in Precision Medicine among the target professions?

\section{KNOWLEDGE GAP}

Participants initial reaction that offers an understanding of the training programme

\section{Figure 1}

Research questions derived from Kirkpatrick's 4 evaluation model

\begin{tabular}{|c|c|c|c|c|}
\hline $\begin{array}{c}\text { Preparation of } \\
\text { the Focus } \\
\text { Group }\end{array}$ & $\begin{array}{l}\text { Participants } \\
\text { and } \\
\text { Researchers }\end{array}$ & Design & Data Collection & Data Analysis \\
\hline $\begin{array}{l}\text { Explore the topic } \\
\text { Collect data on } \\
\text { research } \\
\text { questions } \\
\text { Consider key } \\
\text { themes } \\
\text { Pilot of } \\
\text { questions } \\
\text { Practice Session }\end{array}$ & $\begin{array}{l}\text { Define the study } \\
\text { population } \\
\text { Purposeful } \\
\text { sampling } \\
\\
\text { Select roles } \\
\text { among } \\
\text { researchers }\end{array}$ & $\begin{array}{l}\text { Agenda for the } \\
\text { Focus Groups } \\
\text { Planned } \\
\text { activities }\end{array}$ & $\begin{array}{l}\text { Delivery of Focus } \\
\text { Group sessions } \\
\text { Alignment } \\
\text { across focus } \\
\text { groups } \\
\text { Rules }\end{array}$ & $\begin{array}{l}\text { Transcript \& } \\
\text { Translation } \\
\text { Methodological } \\
\text { frameworks } \\
\text { Concept Map }\end{array}$ \\
\hline
\end{tabular}

\section{Figure 2}

A method for FG design adapted from Nagle \& Williams 2013
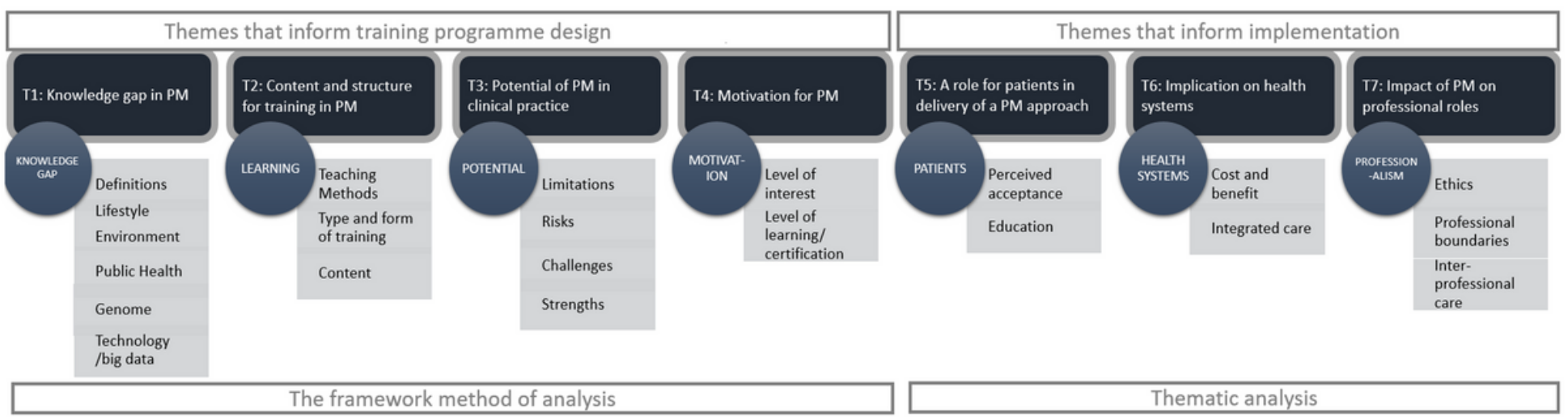
Figure 3

Resultant themes

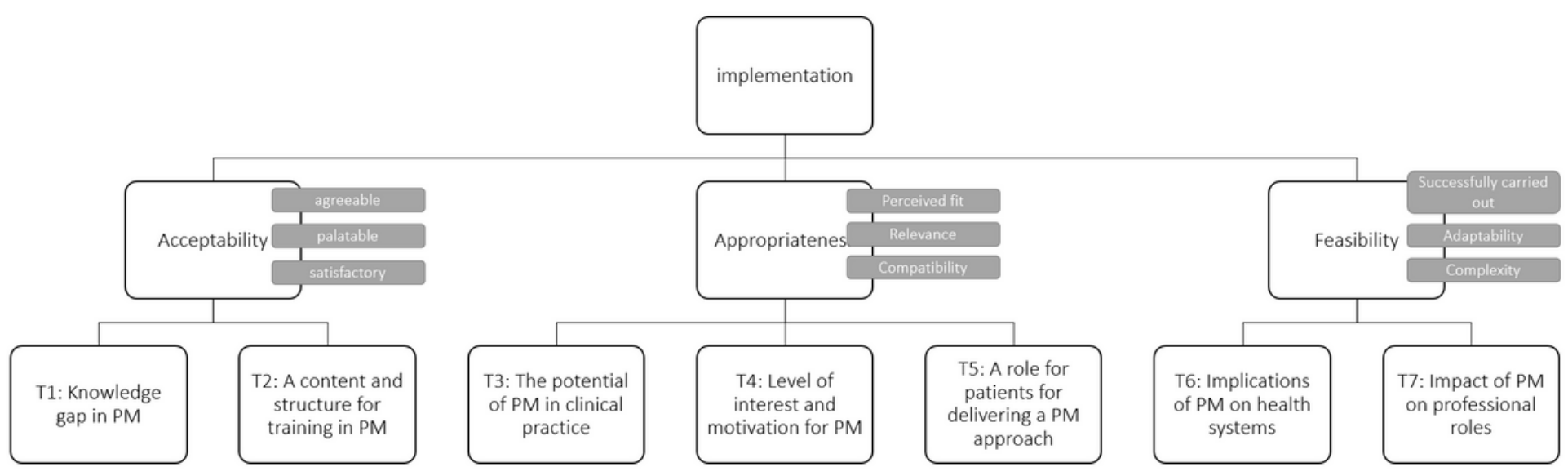

\section{Figure 4}

Key themes linked to implementation outcomes, adapted from Lewis et al. 2015 and Weiner et al 2017 $[62,63]$

\section{Supplementary Files}

This is a list of supplementary files associated with this preprint. Click to download.

- 3NeedsAssessmentUniBernSupplementaryMaterialsBMC.docx

- Appendix.docx 